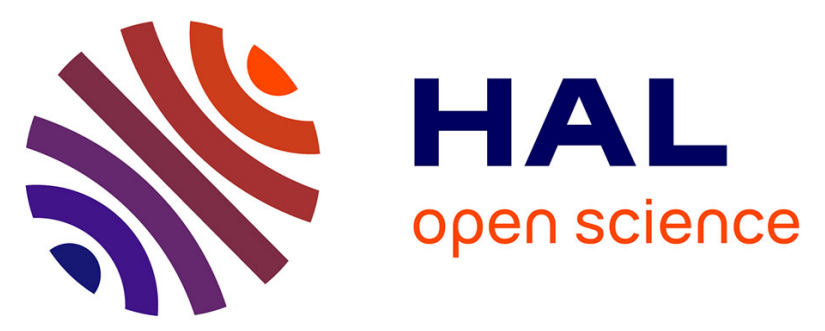

\title{
ASSESSMENT OF A MULTIPLE QUANTUM WELL AND A SUPERLATTICE STRUCTURE BY SPECTROSCOPIC ELLIPSOMETRY, ELECTROREFLECTANCE AND PHOTOREFLECTANCE MODULATION SPECTROSCOPY
}

\author{
M. Erman, C. Alibert, J. Cavaillès, P. Frijlink, C. Bouche
}

- To cite this version:

M. Erman, C. Alibert, J. Cavaillès, P. Frijlink, C. Bouche. ASSESSMENT OF A MULTIPLE QUANTUM WELL AND A SUPERLATTICE STRUCTURE BY SPECTROSCOPIC ELLIPSOMETRY, ELECTROREFLECTANCE AND PHOTOREFLECTANCE MODULATION SPECTROSCOPY. Journal de Physique Colloques, 1987, 48 (C5), pp.C5-139-C5-142. 10.1051/jphyscol:1987526 . jpa00226730

\author{
HAL Id: jpa-00226730 \\ https://hal.science/jpa-00226730
}

Submitted on 1 Jan 1987

HAL is a multi-disciplinary open access archive for the deposit and dissemination of scientific research documents, whether they are published or not. The documents may come from teaching and research institutions in France or abroad, or from public or private research centers.
L'archive ouverte pluridisciplinaire HAL, est destinée au dépôt et à la diffusion de documents scientifiques de niveau recherche, publiés ou non, émanant des établissements d'enseignement et de recherche français ou étrangers, des laboratoires publics ou privés. 
ASSESSMENT OF A MULTIPLE QUANTUM WELL AND A SUPERLATTICE STRUCTURE BY SPECTROSCOPIC ELLIPSOMETRY, ELECTROREFLECTANCE AND PHOTOREFLECTANCE MODULATION SPECTROSCOPY

\author{
M. ERMAN, C. ALIBERT*, J.A. CAVAILLÈs, P. FRIJLINK and \\ C. BOUCHE* \\ Laboratoires d'Electronique et de Physique Appliquée (1) \\ 3. Avenue Descartes, F-94451 Limeil-Brévannes Cedex, France \\ "Université des Sciences et Techniques du Languedoc. Equipe \\ Micro-Opto-Electronique, Place Eugène Bataillon, \\ F-34060 Montpellier Cedex, France
}

Résumáe Utilisant l'ellipsométrie spectroscopique, l'électroreflexion et la photoréflexion, nous avons analysé une structure mul ticouche GaAlAs/GaAs. L'échantillon présente un gradient d'épaisseur parallèlement au diamètre de la plaquette. Grâce à cette non-uniformitè, nous avons pu observer l'évolution continue entre une structure type puits quantiques multiples et type super-réseau.
Abstract
A GaAlAs/GaAs mul tiple quantum well structure exhibiting a thickness gradient over the wafer surface has been analyzed using spectroscopic ellipsametry, electroreflectance and photoreflectance. Due to the sample non uniformity, we have been able to observe the continuous transition from multiple quantum well regime to superlattice regime.

Introduction A GaAlAs/GaAs mul tiple quantilm well (MOW) structure grown by organometalTic chemical vapor phase epitaxy has been analyzed using spectroscopic ellipsometry (SE), electroreflectance (ER) and photoreflectance (PR). The sample, consisting of 25 periods of GaAlAs and GaAs layers (Figure 1), has been grown on half of a two inches $n+$ doped GaAs substrate. The growth conditions have been set so that the sample exhibits a thickness gradient along the diameter of the wafer, while the GaAlAs/GaAs interfaces are still sharp within one monolayer. The purpose of our study is to use this thickness non unifomity to observe the evolution of the spectra vs quantum well and GaAl As barrier thicknesses. As the barrier thickness decreases the sample should allow for the observation of the coupling between quantum wells.

Ellipsometry The sample has been first analyzed using high laterally resotved ellipsometry. This technique determines the ratio between the reflection coefficient of light polarized parallel $\left(r_{p}\right)$ and perpendicular $\left(r_{s}\right)$ to the plane of incidence. The actualiy measured parameters are $\tan (\psi)$ and $\cos (\Delta)$ wich are related to $\rho$ by :

$$
\rho=r_{p} / r_{s}=\tan (\psi) \exp (i \Delta)
$$

The sample has been scanned in energy from $1.4 \mathrm{eV}$ to $4 \mathrm{eV}$ and in position over a $46 \mathrm{~mm}$ line. Figure 2 shows one typical experimental spectrum. We have used such spectra for both analyzing the multilayer structure of the sample (thicknesses, Al composition and interface quality) and measuring the energy position of various excitonic features of the MQW. As observed on Figure 2, experimental spectra exhibit two regions of interest :

- at low energies ( $E<2.3 \mathrm{eV}$ ) interferences due to the total thickness of the MOW are observed.

- at high energies $(2.8<\mathrm{E}<3 \mathrm{eV})$ the absorption of both GaAs and GaAlAs is high and only a few layers close to the surface contribute to

(1) LEP : A member of the Philips Research organization 
optical spectra (1). Multilayer modelling of this part of the spectra allows for the determination of the Al concentration, the localisation energy of the $E_{1}$ transition and the thicknesses of the top iayers (2). In particular, found the ratio $d_{2} / d_{3}$ to be 1.025 and the Al concentration $64 \%$. These two parameters do not vary over the wafer. The variation of the quantum 11 thickness $v s$ the position $X$ is reported on Figure 1.

The excitonic transitions associated with each sub-band are responsible for sharp structures which in SE spectra appear as perturbations of the low energy interference patterns. We have determined the energy of these transitions considering the first derivative of the effective dielectric function (3).

Figure 3 summarizes our results. The first three heavy hole-electron transitions (1abeled 1,2 and 3) are observed when the quantum well thickness is large enough. For a barrier width of $30 \AA$, the electron and the hole wave functions overlap and the levels 1 and 1 ' (i.e. light hole-electron transition) split to form a sub-band. The lowest energy levels correspond to a symmetric wave function $\left(1_{s}\right.$ and $\left.1^{\prime} s\right)$ and the highest energy level (i.e. the upper edge of the sub-band) to the anti-symmetric wave function $\left(1_{a}\right.$ and $\left.1^{\prime} a\right)$. The theoretical curves on figure 3 have been calculated using the classical Kronig-Penney model (3). A good agreement between our experimental data and the model is found for a $60 \%$ conduction band nffset. Photoreflectance and electroreflectance

ER and PR have been proven to be very useful for the study of $Q W$ structures $(2,4)$. In $P R$ the modulation is provided by a chopped beam (HeNe $1 \mathrm{~mW}$ laser) wile in ER the electric field in the structure is modulated via a transparent electrode. One of the advantages of $P R$ over $E R$ is that it is contactless. On the other hand, in PR, complicated modulation mechanisms are associated with carrier injection and are still not completely understood.

Figure 4 shows two typical PR sigectra: tive ton spectruin corresponds to the MQW part of the sample $\left(d_{2}=77 \AA\right)$ while the bottom one has been recorded on the superlattice region. The arrows indicate the transitions aiready observed and assigned in SE (see Fig. 3). The agreement between SE and $P R$ is very good. However, more and better resolved structures can be seen on PR spectra. The structures at $1.42 \mathrm{eV}$ can be associated to GaAs (both cladding layer and substrate). The other lines correspond to excitonic transitions and clearly shift with position on the sample (i.e. with the quantum well and barrier thickness). The strong line at $1.96 \mathrm{eV}$ is the scattered HeNe light. On the bottom GaAs line, Franz-Keldysh oscillations (FKO) indicate a strong built-in electric field. This complicates the lineshape analysis and makes the classical "third derivative" curve fitting inadequate (5).

Figure 5 shows ER spectra recorded at the same positions as previous PR spectra. The electric field was modulated by varying the voltage between -25 and OV. A $-25 \mathrm{~V}$ bias corresponds to $10 \mathrm{w}$ electric field whereas a strong built-in electric field is present at zero bias (see above). The spectrum obtained for $d_{2}=77 \AA$ (Fig. 5a) compares well with the PR one and the SE data. However, ER spectra have been recorded up to $3.2 \mathrm{eV}$ allowing for the observation of Ga. $36 \mathrm{Al} \cdot 64 \mathrm{As} E_{0}$ structure as well as the $E_{1}$ transition of the $Q W$. The second spectrum $\left(d_{2}=18.7 \mathrm{~A}\right)$ exhibits some differences with $P R$. The origin of these discrepancies can only be undestood by comparing spectra obtained at different positions and by varying the static component of the electric field in the structure (i.e. changing the offset in the applied voltage). Corresponding results will be published el sewhere.

\section{References :}

1/ M. Erman, J.B. Theeten, N. Vodjdani and Y. Demay, J. Vac. Sci. Technol. B, (1983) 328

2/ M. Erman, J.B. Theeten, P. Frijlink, S. Gaillard, Fan Jia Hia and

C. Al ibert, J. Appl. Phys. 56, (1984) 3241

3/ M. Erman, C. Alibert, J.B. Theeten, P. Frijlink and B. Catte, to be published in J. Appl. Phys.

4/ 0.J. Glembocki, B.V. Shanabrook, N. Bottka, W.T. Beard and J. Comas, SPIE Vo1. 524, (1985) 86

5/ P. Parayantha1, H. Shen, F.H. Pollak, O.J. Glembocki, B.V. Shenabrook and W.T. Beard, Appl. Phys. Lett. 48, (1986) 1261 

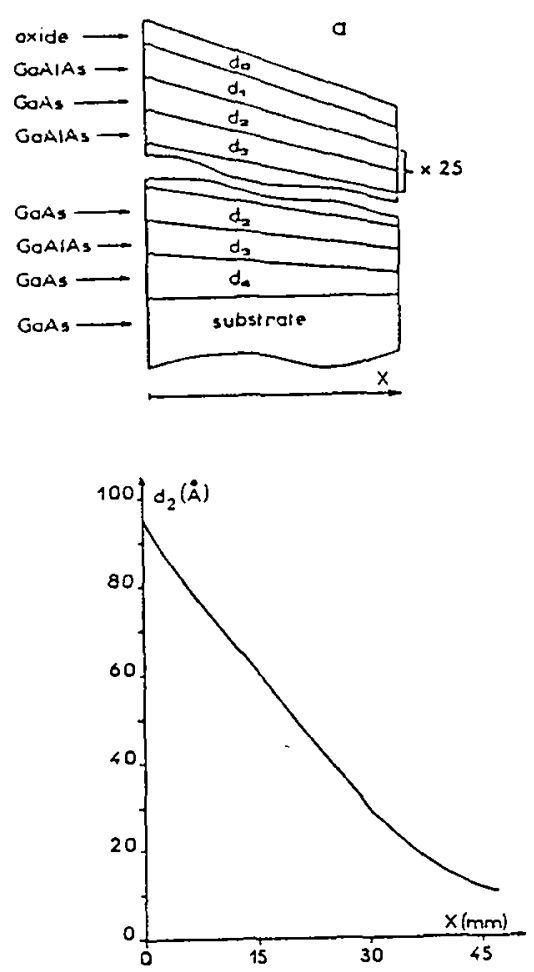

Figure1: Schematic representation of the sample $(a)$ and the quantum well thickness de vs position $X$ along the strongest thickness gradient line, as deduced from SE analysis (b).

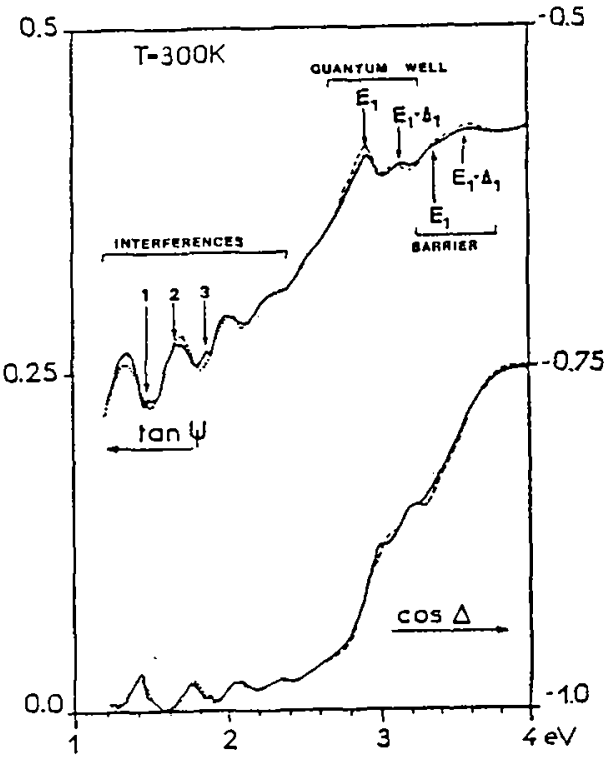

Figure2: One example of masured SE spectra. Dotted lines represent a multilayer model fit of the interference patterns at low energy $(1.2-2.2 \mathrm{eV})$. Weak structures, superimposed to interference regime are due to the optical transitions in the MOW. The $E_{1}$ and $E_{1}+\Delta_{1}$ structures of GaAs and Ga.36Al.64As are observed at higher energies.

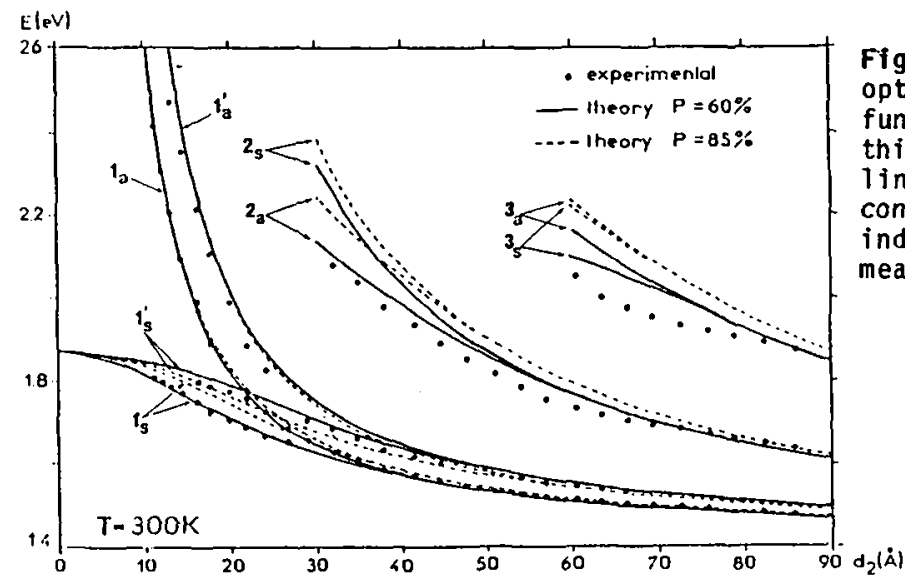

Figure3: Energy of the optical transitions as a function of the quantum well thickness do for $60 \%$ (full line) and $85 \%$ (dashed line) conduction band offset. Dots indicate experimentally measured structures. 


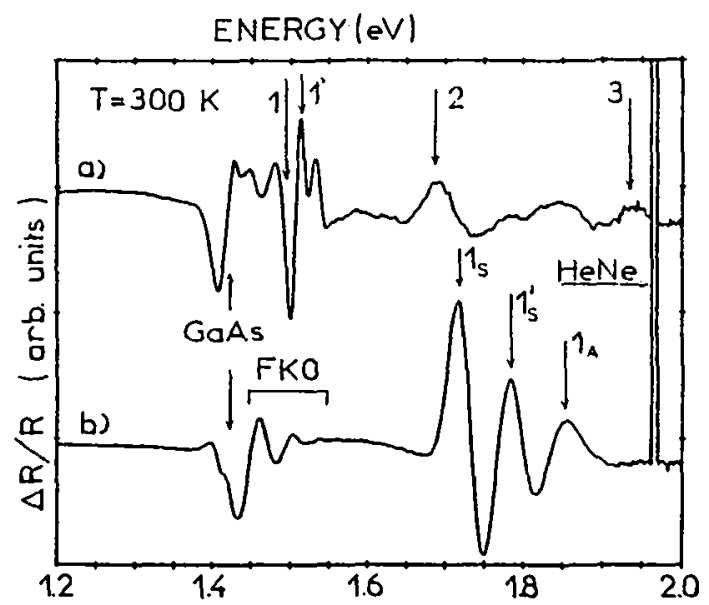

Figure 4 : Photoreflectance spectra recorded at positions where the well thickness is $77 \AA$ (a) and $19 \AA$ (b). Arrows indicate transitions determined by spectroscopic

ellipsometry. Note the clear Franz Keldysh oscillations (FKO) near the GaAs structure on curve $b$.

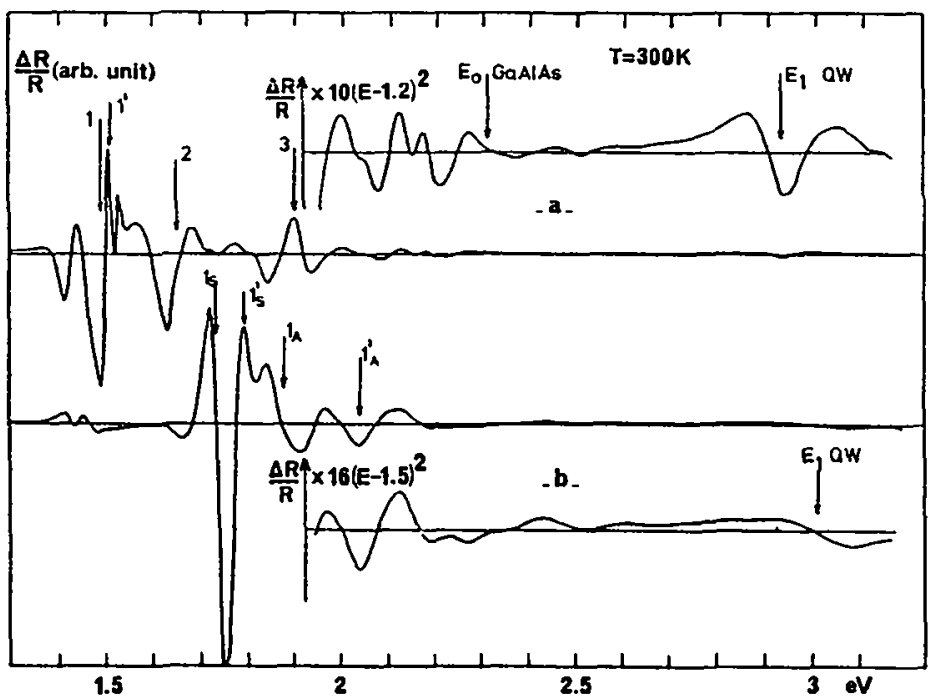

Figure 5 : Electroreflectance spectra recorded at positions where the well thickness is $77 \AA$ (a) and $19 \AA$ (b). As in Figure 4 , arrows indicate transitions determined by SE. In the insets, the $\Delta R / R$ signal is multiplied by an energydependent tem in order to enhance high energy structures without introducing discontinuities in the spectra. 